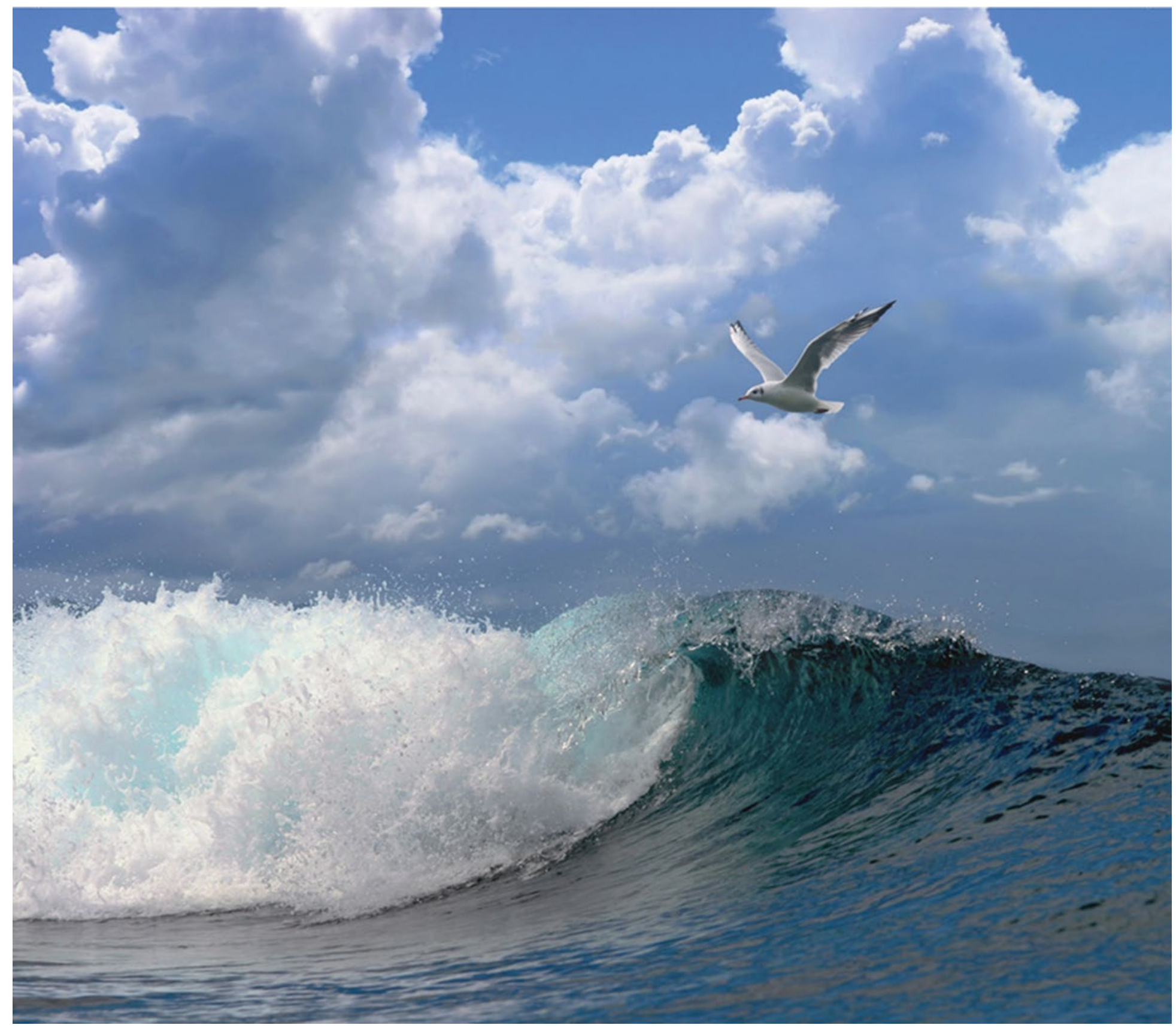

Bestandsopname van mosselen op mosselkweekpercelen in de Waddenzee in juni-juli 2019 


\section{Bestandsopname van mosselen op mosselkweekpercelen in de Waddenzee in juni-juli 2019}

Auteur(s): Jacob J. Capelle en Marnix R. van Stralen

Publicatiedatum: 23 Augustus 2019 
Jacob J. Capelle, Marnix, R. van Stralen, 2019. Bestandsopname van mosselen op mosselkweekpercelen in de Waddenzee in juni-juli 2019. Wageningen Marine Research Wageningen UR (University \& Research centre), Wageningen Marine Research rapport C079/19. 20 blz.

Keywords: mosselbestand, mosselkweek, Waddenzee

Opdrachtgever: Ministerie van LNV en PO Mosselcultuur

Dit rapport is gratis te downloaden van https://doi.org/10.18174/498641

Wageningen Marine Research verstrekt geen gedrukte exemplaren van rapporten.

Wageningen Marine Research Wageningen UR is ISO 9001:2008 gecertificeerd.

(C) 2016 Wageningen Marine Research Wageningen UR

Wageningen Marine Research, onderdeel van Stichting Wageningen Research KvK nr. 09098104,

IMARES BTW nr. NL 8113.83.696.B16. Code BIC/SWIFT address: RABONL2U IBAN code: NL 73 RABO 0373599285
De Directie van Wageningen Marine Research is niet aansprakelijk voor gevolgschade, noch voor schade welke voortvloeit uit toepassingen van de resultaten van werkzaamheden of andere gegevens verkregen van Wageningen Marine Research opdrachtgever vrijwaart Wageningen Marine Research van aanspraken van derden in verband met deze toepassing.

Dit rapport is vervaardigd op verzoek van de opdrachtgever hierboven aangegeven en is zijn eigendom. Niets uit dit rapport mag weergegeven en/of gepubliceerd worden, gefotokopieerd of op enige andere manier gebruikt worden zonder schriftelijke toestemming van de opdrachtgever. 


\section{Inhoud}

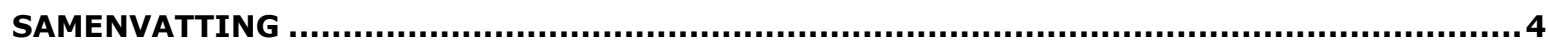

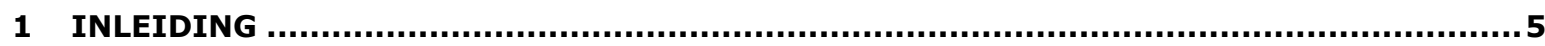

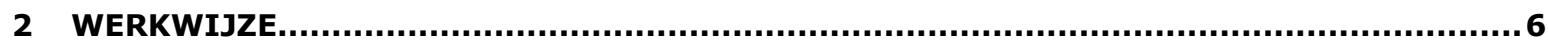

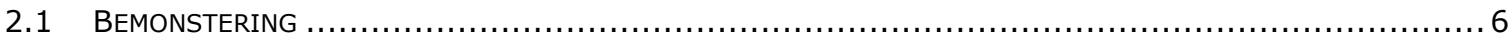

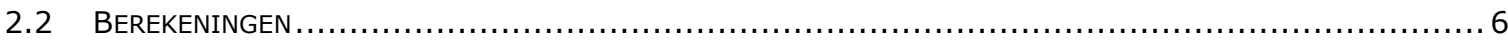

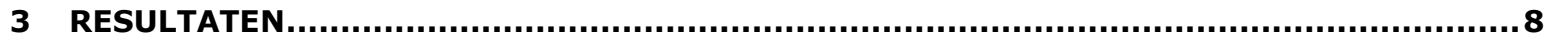

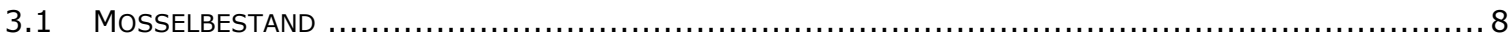

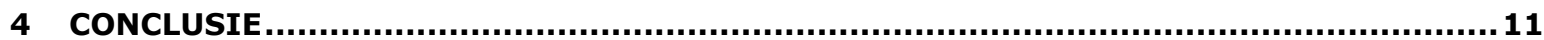

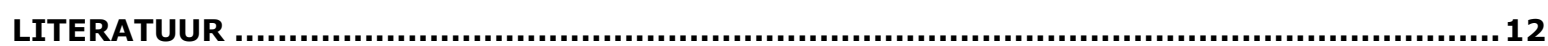

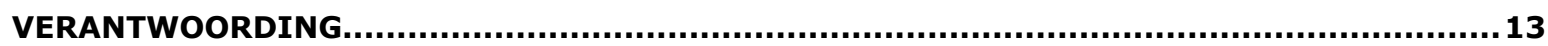

BIJLAGE 1 WERKVOORSCHRIFT MONSTERNAME .......................................................... 14

BIJLAGE 2 KAARTEN MOSSELDICHTHEID PER GROOTTEKLASSE ..................................16 


\section{Samenvatting}

Een van de uitgangspunten bij de mosselzaadvisserij is dat de omvang van het mosselbestand in de Waddenzee en daarmee het voedselaanbod voor vogels niet minder is dan in een situatie dat er niet wordt gekweekt en gevist. Dat betekent dat in het najaar een zekere hoeveelheid mosselen op de kweekpercelen in de Waddenzee aanwezig dient te zijn. Na de voorjaarsvisserij wordt met een bestandsopname een schatting gemaakt van het bestand op de kweekpercelen (de zogenaamde 'starthoeveelheid') en wordt vervolgens bijgehouden hoeveel mosselen afgevoerd worden en hoeveel mosselen erbij komen. Een tweede bestandsopname is bedoeld om te kunnen valideren of de eerder genoemde hoeveelheid mosselen aan het begin van de winter inderdaad op de percelen aanwezig is. In voorliggende rapportage wordt de bestandsopname op de percelen na de voorjaarszaadvisserij van 2019 gerapporteerd. Hiertoe zijn alle kweekpercelen in de Waddenzee waar mosselen verwacht worden in juni-juli 2019 bemonsterd. Het totale bestand op de percelen na de voorjaarsvisserij 2019 is geschat op $\mathbf{9 4 , 1}$ miljoen $\mathbf{~ k g ~ n e t t o ~ e n ~} \mathbf{1 4 4 , 8}$ miljoen $\mathbf{~ k g}$ bruto. Het totale bestand is hiermee hoger dan gemiddeld in het voorjaar (sinds het begin van de metingen in 2013). 


\section{$1 \quad$ Inleiding}

Eén van de uitgangspunten voor de mosselzaadvisserij is dat het geheel van vissen, kweek en afvoer van mosselen naar Zeeland ('VKA') niet leidt tot minder mosselen in de Waddenzee en daarmee tot minder voedsel voor overwinterende vogels dan in een situatie waarin niet zou worden gekweekt en gevist. De achtergronden hiervan zijn na te lezen in de passende beoordeling voor de mosselzaadvisserij (van Stralen, 2018) en de NB-wet vergunning die voor de periode 2018-2020 door het ministerie van Economische Zaken voor deze visserij is verleend (LNV, 2018).

Dit uitgangspunt betekent dat er in het najaar een zekere minimale hoeveelheid mosselen op de percelen aanwezig moet zijn. Voor het najaar van 2019 is dit minimale mosselbestand vastgesteld op 31.8 Miljoen $\mathrm{kg}(318.000$ mosselton $(\mathrm{mt}=100 \mathrm{~kg})$ ) netto versgewicht mosselen (Marinx-notitie, 5 juni 2019, bijlage bij de vergunning voorjaarsvisserij 2019). Om dat te borgen wordt na de voorjaarsvisserij een schatting gemaakt van het bestand op de kweekpercelen (de zogenaamde 'starthoeveelheid') en wordt vervolgens bijgehouden hoeveel mosselen naar Zeeland worden afgevoerd en hoeveel mosselen erbij komen afkomstig uit MZI's, zaadvisserij in het najaar en andere bronnen (bijvoorbeeld 'Zuid-Noord' transporten, d.w.z. transporten van mosselen uit Zeeland naar de Waddenzee). Met een tweede bestandsopname in de winter, wordt gevalideerd of de vastgestelde minimale hoeveelheid mosselen aan het begin van de winter inderdaad op de percelen aanwezig is.

Het mosselbestand op de percelen na de voorjaarsvisserij (die plaats vond in week 18-22) van 2019 is geïnventariseerd van 25 juni tot en met 12 juli 2019. De resultaten van de inventarisatie worden hier gerapporteerd. Voor eventuele veranderingen in het bestand door groei, sterfte en/of afvoer van mosselen in de periode tussen de voorjaarsvisserij in mei en de survey is niet gecorrigeerd. 


\section{Werkwijze}

\section{$2.1 \quad$ Bemonstering}

Alle kweekpercelen in de Waddenzee waar mosselen verwacht worden, zijn in juni 2018 bemonsterd. De bestandsopname is uitgevoerd zoals beschreven is in Van Stralen (2013). Hiervoor zijn bemonsteringsstations volgens een regelmatig grid over de kweekpercelen verdeeld. De bemonsteringsstations liggen in noordelijke en oostelijke richting 0,2 nautische minuten van elkaar, overeenkomend met een gridceloppervlakte van 8,26 ha. Kweekpercelen of gedeelten van kweekpercelen die in de winter niet voor mosselkweek gebruikt worden, zijn hierbij uitgesloten. Er is in de bemonstering gebruik gemaakt van hetzelfde grid als voor de bemonstering in de zomer en winter van 2017 \& 2018. Uitgangspunten voor de vaststelling van dit grid zijn beschreven in (Troost \& Van Stralen, 2017).

In totaal zijn 527 stations bemonsterd tussen 28 juni en 12 juli 2019 door buitendienst medewerkers van de Waddenunit van het Ministerie van EZ vanaf de Rijksvaartuigen "Asterias" en "Phoca". Per station zijn 5 happen genomen met een Van Veen bodemhapper wat resulteert in een bemonsterd oppervlak van $0,276 \mathrm{~m}^{2}$ per station.

De vijf happen genomen per monsterstation zijn samengevoegd tot één monster voor het uitzoeken van mosselen, zeesterren en krabben. Per monsterstation is het volume (in liters) van de mosselen bepaald. Per dag zijn de vangsten aan mosselen bijeengevoegd. Stations met vooral mosselzaad als vangst zijn daarbij apart gehouden van stations met voornamelijk halfwas (schelplengte kleiner dan $45 \mathrm{~mm}$ ) en/of al voor consumptiegeschikte mosselen (schelplengte van minstens $45 \mathrm{~mm}$ ). Dit levert per dag dus twee verzamelmonsters op: 1) zaad en 2) meerjarige mosselen (halfwas + consumptie). Aan het eind van de dag is van elk daarvan het volume bepaald (in liters) en zijn eventueel deelmonsters genomen voor zaad $(3,5 \mathrm{I})$ en meerjarige mosselen ( $6 \mathrm{I})$. Uit de (deel)monsters wordt het aandeel zaad, halfwas en consumptiegeschikte mosselen geselecteerd. Deze mosselen worden schoongemaakt, ook de hoeveelheid pokken wordt gewogen. Ten slotte worden de schoongemaakte mosselen geteld en gewogen. De handleiding voor de verwerking van deze monsters is bijgevoegd in Bijlage 1.

\subsection{Berekeningen}

Bij het vaststellen van quota en uitmeten van vangsten bij de zaadvisserij maar ook bij het verplaatsen van bijvoorbeeld halfwasmosselen naar Zeeland wordt gerekend in bruto gewichten - dit zijn mosselen inclusief tarra, zoals wier, pokken, zeesterren en schelpresten. Er zijn daarom ook bruto bestandsschattingen gemaakt. Bij de doorrekening van netto naar bruto hoeveelheden zaad en meerjarige mosselen is uitgegaan van tarrapercentages van respectievelijk $40 \%$ en $25 \%$. Dit is conform de berekeningen bij bestandsopnamen van wilde mosselbestanden.

Uit de monsters die aan het einde van dag $j$ (de dagvangst) verzameld zijn (voor respectievelijk twee grootteklassen ( $i$ ): meerjarige mosselen en voor zaad) is een deelmonster genomen. De omrekenfactor van dit deelmonster naar het totale dagmonster is uitgerekend door de totale vangst per dag $(V$, liter) te delen door de hoeveelheid deelmonster ( $V d$, liter). Bij deelmonsters met veel (kleine) mosselen is soms slechts een deel van het deelmonster doorgemeten, door het deelmonster in gelijke delen te verdelen. In dat geval is de omrekenfactor vermenigvuldigd met het aantal gelijke delen $(x)$ waarin het deelmonster is verdeeld. De omrekenfactor $(f)$ is dus als volgt opgebouwd: $f_{i, j}=$ $V_{i, j} / V d_{i, j} *_{i, j}$

Van elk deelmonster uit zowel de dagvangst zaad als uit de dagvangst meerjarige mosselen is het gewicht aan mosselen gemeten en het aantal mosselen geteld, hierbij is onderscheid gemaakt tussen 
drie klassen: zaad (jaarklasse 0), halfwas (meerjarig $<30 \mathrm{~mm}$ ) en consumptiemaat (meerjarig $>45 \mathrm{~mm}$ ). Door het gewicht $(\mathrm{kg})$ aan mosselen in het deelmonster te vermenigvuldigen met de bijbehorend omrekenfactor $(f)$ is de biomassa $(\mathrm{kg})$ in het totale dagmonster uitgerekend. Daarmee is geschat wat er per dag aan biomassa zaadmosselen, halfwasmosselen en consumptiemosselen verzameld is. Deze biomassa's zijn gedeeld door het totale verzamelde volume $(V)$ van die dag. Het resultaat is een schatting van de biomassa aan zaadmosselen, halfwasmosselen en consumptiemosselen per liter monster $(\mathrm{kg} / \mathrm{l})$ voor elke dag dat er bemonsterd is.

Per bemonsteringsstation $(n=527)$ is de biomassa mosselen per vierkante meter $\left(B, \mathrm{~kg} / \mathrm{m}^{2}\right)$ geschat uit het verzameld volume $(\mathrm{I})$ aan mosselen per bemonsteringsstation, door dit te vermenigvuldigen met respectievelijk de biomassa aan zaadmosselen, halfwasmosselen en consumptiemosselen per liter monster $(\mathrm{kg} / \mathrm{l})$ voor die dag en dit delen door het bemonsterd oppervlak $(A)$ per station $\left(0,276 \mathrm{~m}^{2}\right)$.

De netto mosselbiomassa in mosselton ( $\mathrm{mt}=100 \mathrm{~kg}$ ) per gridcel $(k)$, is geschat door de biomassa per vierkante meter $\left(B, \mathrm{~kg} / \mathrm{m}^{2}\right)$ te vermenigvuldigen met de oppervlakte van de gridcel $(8,26$ ha) waarin dit monsterpunt zich bevind. De netto mosselbiomassa percelen $(\mathrm{mt})$, per grootteklasse is geschat door de mosselbiomassa's van de gridcellen bij elkaar op te tellen. 


\section{Resultaten}

\subsection{Mosselbestand}

De aangetroffen dichtheden van mosselen zijn ruimtelijk weergegeven in Figuur 3.1. Een opsplitsing voor verschillende grootteklassen is bijgevoegd in Bijlage 2. De bijbehorende bestandsgroottes zijn, samen met de resultaten uit voorgaande jaren, samengevat in Tabel 3.1 en in Figuur 3.2. In Figuur $\mathbf{3 . 3}$ zijn alleen de bemonsteringen die in het voorjaar uitgevoerd zijn weergegeven.

Het mosselbestand op de percelen in de Waddenzee eind juni, begin juli 2019 is geschat op 94,1 miljoen $\mathrm{kg}$ ( 941.000 mosselton, $1 \mathrm{mt}=100 \mathrm{~kg}$ ) netto versgewicht. Daarvan bestaat 57,8 miljoen $\mathrm{kg}$ uit mosselzaad (broedval 2018). Van de 36,3 miljoen $\mathrm{kg}$ meerjarige mosselen bestaat 18,3 miljoen kg uit halfwas mosselen (schelplengte kleiner dan $45 \mathrm{~mm}$ ) en 17,9 miljoen $\mathrm{kg}$ uit consumptiemosselen (schelplengte van minstens $45 \mathrm{~mm}$ ). Uitgaande van tarrapercentages van $40 \%$ en $25 \%$ voor respectievelijk mosselzaad en meerjarige mosselen komt de bruto mosselbiomassa op de percelen uit op 144,8 miljoen $\mathrm{kg}(1.4480 .000 \mathrm{mt}$ ) versgewicht, waarvan 96,4 miljoen $\mathrm{kg}$ mosselzaad en 48,4 miljoen $\mathrm{kg}$ meerjarige mosselen.

Tabel 3.1. Het mosselbestand op mosselkweekpercelen in de Waddenzee vanaf 2004. Bij de omrekening van netto naar bruto hoeveelheden is voor mosselzaad en meerjarige mosselen uitgegaan van een tarrapercentage van resp. 45\% en 25\%. 1 Mosselton $(\mathrm{mt})=100 \mathrm{~kg}$. De gegevens tot en met 2011 zijn afkomstig uit (De Mesel \& Wijsman, 2011) en (Wijsman \& Jol, 2012).

\begin{tabular}{|c|c|c|c|c|c|c|c|c|}
\hline \multirow{2}{*}{$\begin{array}{l}\text { Mosselbestand } \\
\text { kweekpercelen } \\
\text { Waddenzee }\end{array}$} & \multicolumn{4}{|c|}{ Netto bestand (miljoen kg) } & \multicolumn{4}{|c|}{ Bruto bestand (mt x 1000) } \\
\hline & Zaad & $\begin{array}{l}\text { Halfwas } \\
(<45 \mathrm{~mm})\end{array}$ & $\begin{array}{c}\text { Groot } \\
(\geq 45 \mathrm{~mm})\end{array}$ & Totaal & Zaad & $\begin{array}{l}\text { Halfwas } \\
(<45 \mathrm{~mm})\end{array}$ & $\begin{array}{c}\text { Groot } \\
(\geq 45 \mathrm{~mm})\end{array}$ & Totaal \\
\hline $2004-$ dec & 1,0 & 15,2 & 31,9 & 48,1 & 17 & 203 & 425 & 644 \\
\hline 2005- dec & 8,9 & 0,9 & 5,2 & 14,9 & 148 & 12 & 69 & 228 \\
\hline 2006- dec & 1,0 & 5,8 & 29,0 & 35,8 & 17 & 77 & 387 & 481 \\
\hline 2007- dec & 17,5 & 2,5 & 15,3 & 35,3 & 291 & 33 & 204 & 528 \\
\hline 2008- dec & 11,8 & 2,1 & 15,8 & 29,7 & 196 & 28 & 211 & 435 \\
\hline 2009- dec & 15,4 & 2,8 & 28,3 & 46,5 & 257 & 38 & 377 & 672 \\
\hline 2010- dec & 7,6 & 11,0 & 28,9 & 47,5 & 127 & 147 & 385 & 659 \\
\hline $2011-$ dec & 8,9 & 1,3 & 11,8 & 21,9 & 148 & 17 & 157 & 322 \\
\hline $2013-$ jan & 39,6 & 1,5 & 5,6 & 46,7 & 660 & 20 & 74 & 754 \\
\hline 2013 - april & 52,5 & 1,7 & 4,7 & 58,9 & 875 & 23 & 62 & 960 \\
\hline $2013-\mathrm{dec}$ & 14,3 & 31,1 & 4,7 & 50,1 & 238 & 415 & 63 & 716 \\
\hline 2014 - juli & 7,5 & 33,3 & 20,3 & 61,1 & 124 & 444 & 271 & 840 \\
\hline $2014-$ dec & 37,7 & 7,6 & 13,4 & 58,7 & 629 & 101 & 179 & 909 \\
\hline 2015 - juni & 40,7 & 11,7 & 13,5 & 65,8 & 678 & 155 & 180 & 1013 \\
\hline $2015-$ dec & 45,6 & 9,5 & 12,4 & 67,5 & 761 & 126 & 165 & 1052 \\
\hline 2016 - juni & 62,6 & 21,3 & 15,2 & 99,1 & 1044 & 284 & 202 & 1530 \\
\hline $2017-$ feb & 48,1 & 14,6 & 9,1 & 71,8 & 802 & 195 & 121 & 1118 \\
\hline 2017 - juli & 80,3 & 20,4 & 18,0 & 118,8 & 1339 & 272 & 240 & 1851 \\
\hline $2018-$ feb & 20,8 & 20,2 & 9,3 & 50,4 & 346 & 270 & 125 & 741 \\
\hline 2018 - juni & 25,0 & 22,3 & 23,7 & 71,0 & 416 & 297 & 316 & 1030 \\
\hline $2018-$ dec & 52,9 & 11,3 & 27,3 & 91,5 & 881 & 151 & 364 & 1396 \\
\hline 2019 - jun/jul & 57,8 & 18,3 & 17,9 & 94,1 & 964 & 244 & 239 & 1448 \\
\hline gem. voorjaar '13-'19 & 46,6 & 18,4 & 15,9 & 16,2 & 777 & 246 & 216 & 1239 \\
\hline gem. winter '04-'19 & 22,1 & 9,2 & 16,5 & 44,2 & 368 & 122 & 220 & 710 \\
\hline
\end{tabular}



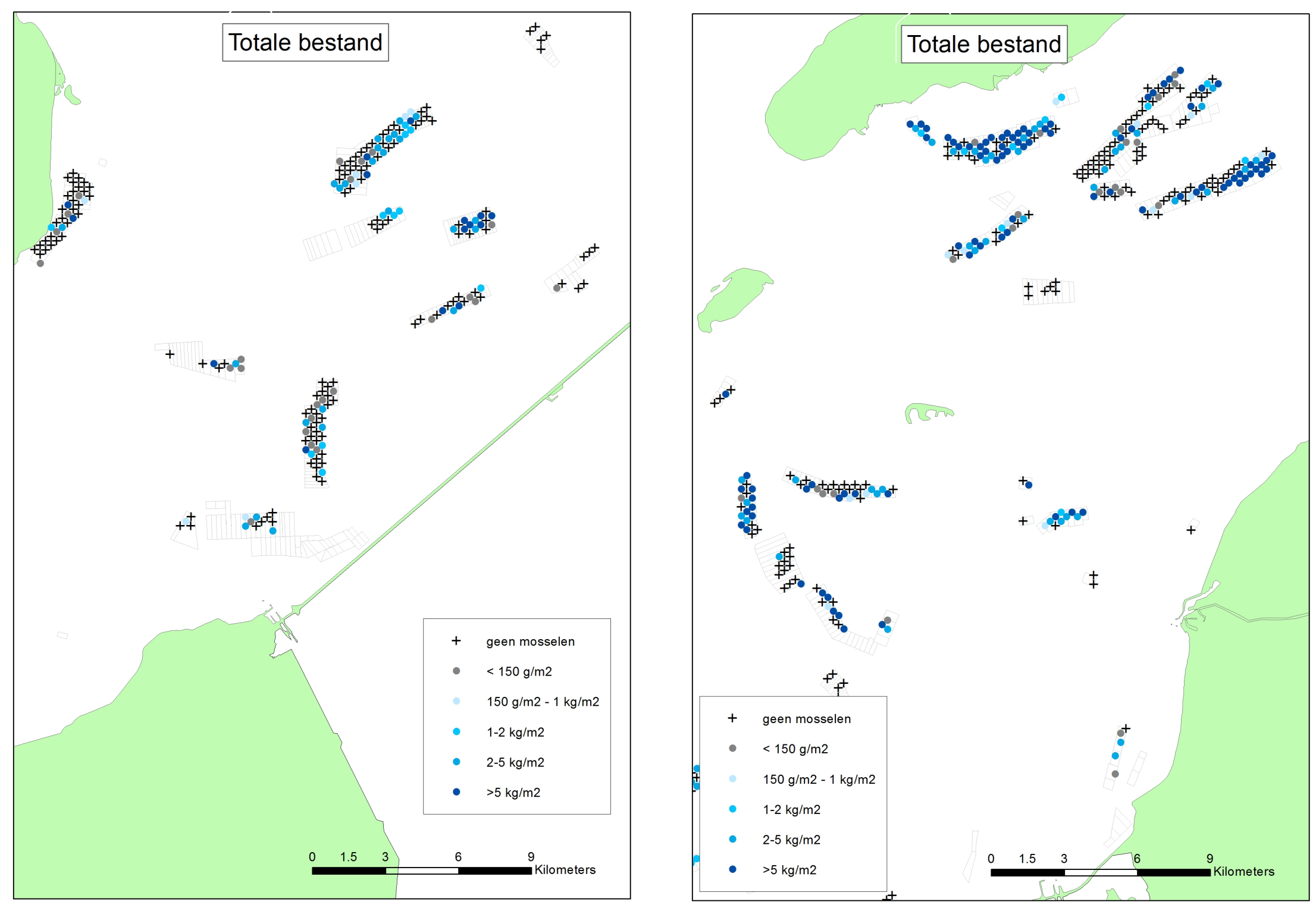

Figuur 3.1 Dichtheid van mosselen op mosselkweekpercelen in de Waddenzee (links kombergingsgebied Marsdiep en rechts kombergingsgebied Vlie) in juni - juli 2019 in gram versgewicht per $\mathrm{m}^{2}$. 


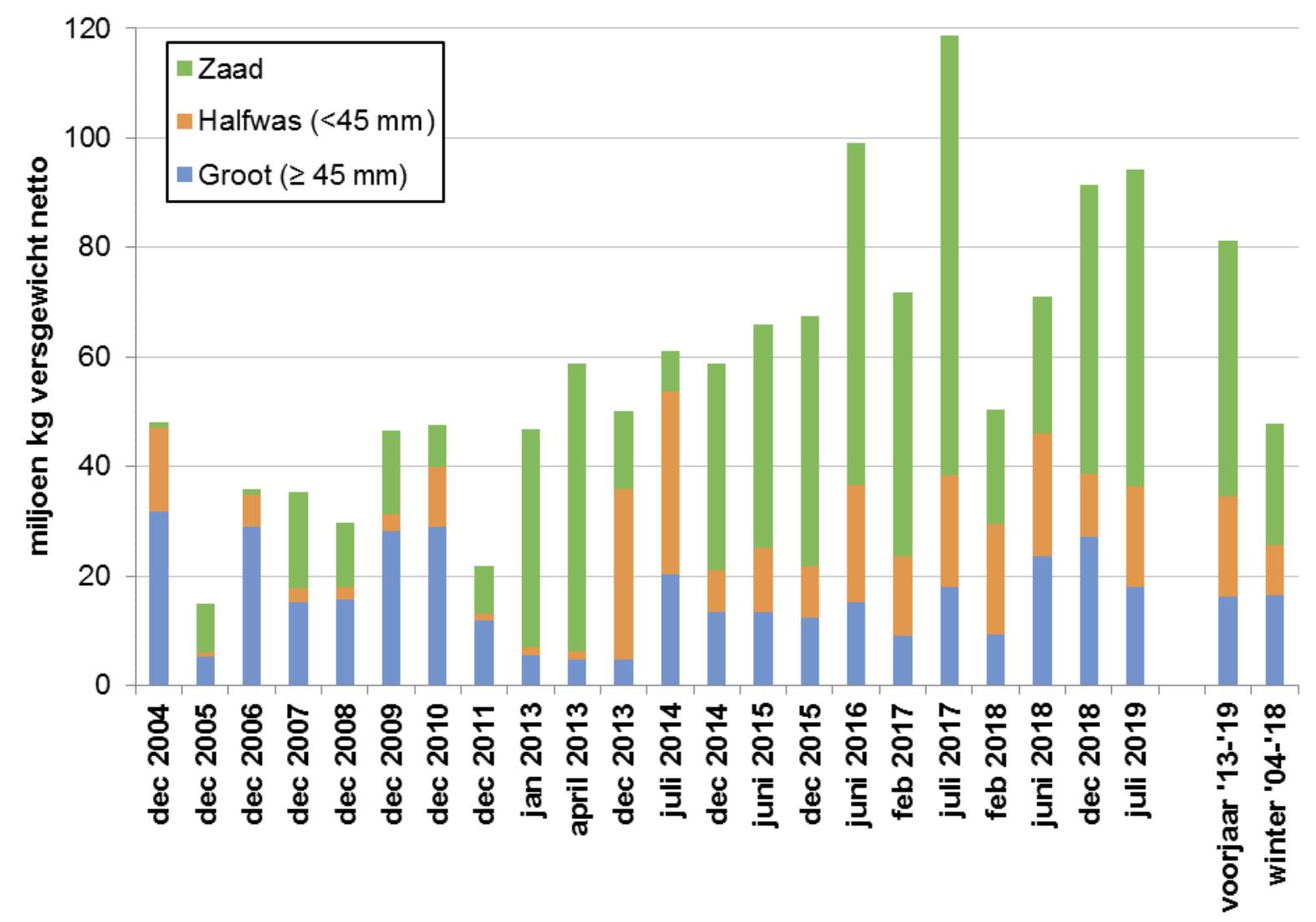

Figuur 3.2 Mosselbestand in miljoen kg netto versgewicht op mosselkweekpercelen in de Waddenzee in de periode december 2004 - juli 2019 met meest rechts de gemiddelde biomassa in het voorjaar van 20132019 en in de winters van 2004 - 2018. De mosselen zijn onderverdeeld in mosselzaad en meerjarige mosselen groter en kleiner dan $45 \mathrm{~mm}$. De onderliggende gegevens zijn opgenomen in Tabel 3.1.

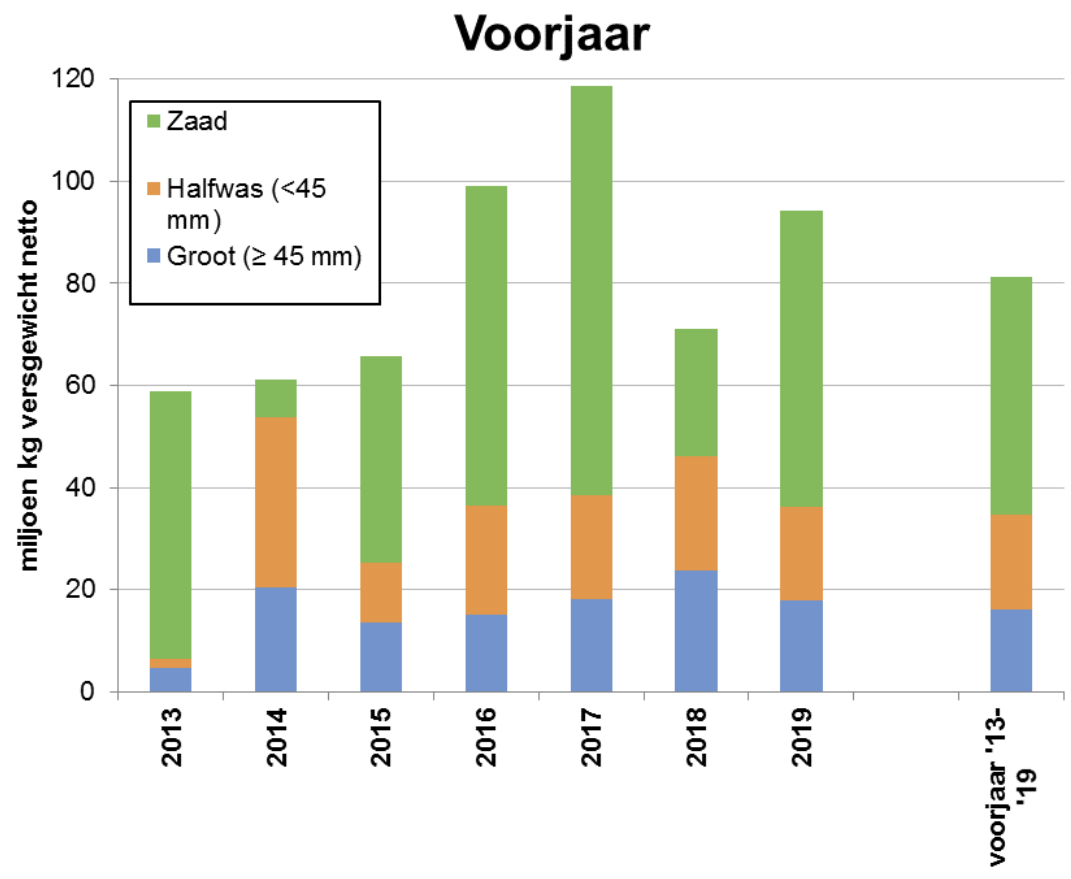

Figuur 3.3 Mosselbestand in miljoen $\mathrm{kg}$ netto versgewicht op mosselkweekpercelen in de Waddenzee in het voorjaar vanaf 2013. De mosselen zijn onderverdeeld in mosselzaad en meerjarige mosselen groter en kleiner dan $45 \mathrm{~mm}$. 


\section{$4 \quad$ Conclusie}

Het mosselbestand op de percelen in de Waddenzee eind juni, begin juli 2019 is met 94,1 Mkg (netto) hoger dan gemiddeld $(81,2 \mathrm{Mkg}$ ) in het voorjaar sinds de metingen begonnen in 2013 en ligt ook ver boven de te garanderen hoeveelheid mosselen op percelen in het najaar van 2019 van $31.8 \mathrm{Mkg}$. 


\section{Literatuur}

De Mesel I, Wijsman JWM (2011) Bestandsschatting mosselen op percelen in de Oosterschelde (1992-2009) en de Waddenzee (2004-2009). Yerseke.

LNV (2018) Nb-wet vergunning voor de mosselzaadvisserijen, 2018-2020. Kenmerk DGAN-NB/18 / 18034015, ministerie van EZ, Den Haag.

Troost K, Van Stralen MR (2017) Bestandsopname van mosselen op mosselkweekpercelen in de Waddenzee in juli 2017, . Wageningen Marine Research Wageningen UR (University \& Research centre), Wageningen Marine Research, rapport C070/17.

Van Stralen MR (2013) Bestandsopname van mosselen op mosselkweekpercelen in de Waddenzee in de winter van 2012-2013. Marinx.

van Stralen MR (2018) Passende Beoordeling van de mosselvisserij in het sublitoraal van de Westelijke Waddenzee in de periode 2018-2020. Marinx, Scharendijke.

Wijsman JWM, Jol J (2012) Onderzoeksproject Duurzame Schelpdiervisserij (PRODUS). Deelproject $1 \mathrm{~A}$. Bepaling bestand op de mosselpercelen in de Waddenzee najaar 2011 (Mussel stock assessment on culture plots in the Waddensea in autumn 2012, report in Dutch). Wageningen IMARES, Yerseke, pp. 48. 


\title{
Verantwoording
}

\author{
Rapport C079/19
}

Projectnummer: 4313200007-07 KOMPRO 1

Dit rapport is met grote zorgvuldigheid tot stand gekomen. De wetenschappelijke kwaliteit is intern getoetst door een collega-onderzoeker en het verantwoordelijk lid van het managementteam van Wageningen Marine Research

Akkoord:

Linda Tonk

DLO onderzoeker

Handtekening:

Datum:

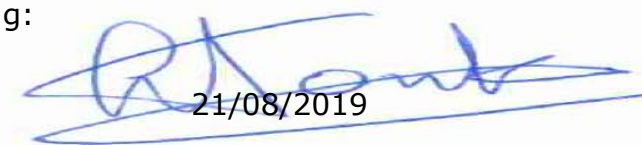

Akkoord:

Drs. J. Asjes

Manager Integratie

Handtekening:

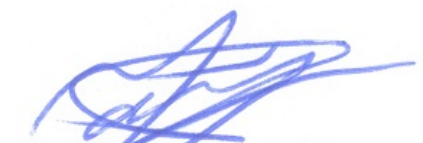

Datum: 


\section{Bijlage 1 Werkvoorschrift monstername}

Handleiding bemonstering mosselpercelen

versie 7 november 2014

\section{Monstername per station}

- Op elk station $\mathbf{5}$ happen

- Bij elkaar in een mand, spoelen

- Zeesterren uit de vangst halen, aantal noteren en bewaren in verzamel-emmer

- Idem voor krabben met schild groter dan $2 \mathrm{~cm}$ (duimnagel)

- Volume van de vangst bepalen in bekerglas. Aflezen in tienden liters. Wanneer het maar een paar mosselen zijn ("bewijsje") een "B" invullen. Wanneer er geen mosselen in de vangst zitten kan tarra over boord en is de vangst "nul".

- Bewaren in verzamelmand Zaad c.q. Halfwas + Cons. Bij mengsel indelen op dominante soort

- Aan dek: sample nummers ("treknummers" van die dag) invullen

- Brug: trek nummers noteren op de kaartjes.

Invullen meetlijst aan dek

De blauwe waarden moeten worden ingevuld, hier als voorbeeld

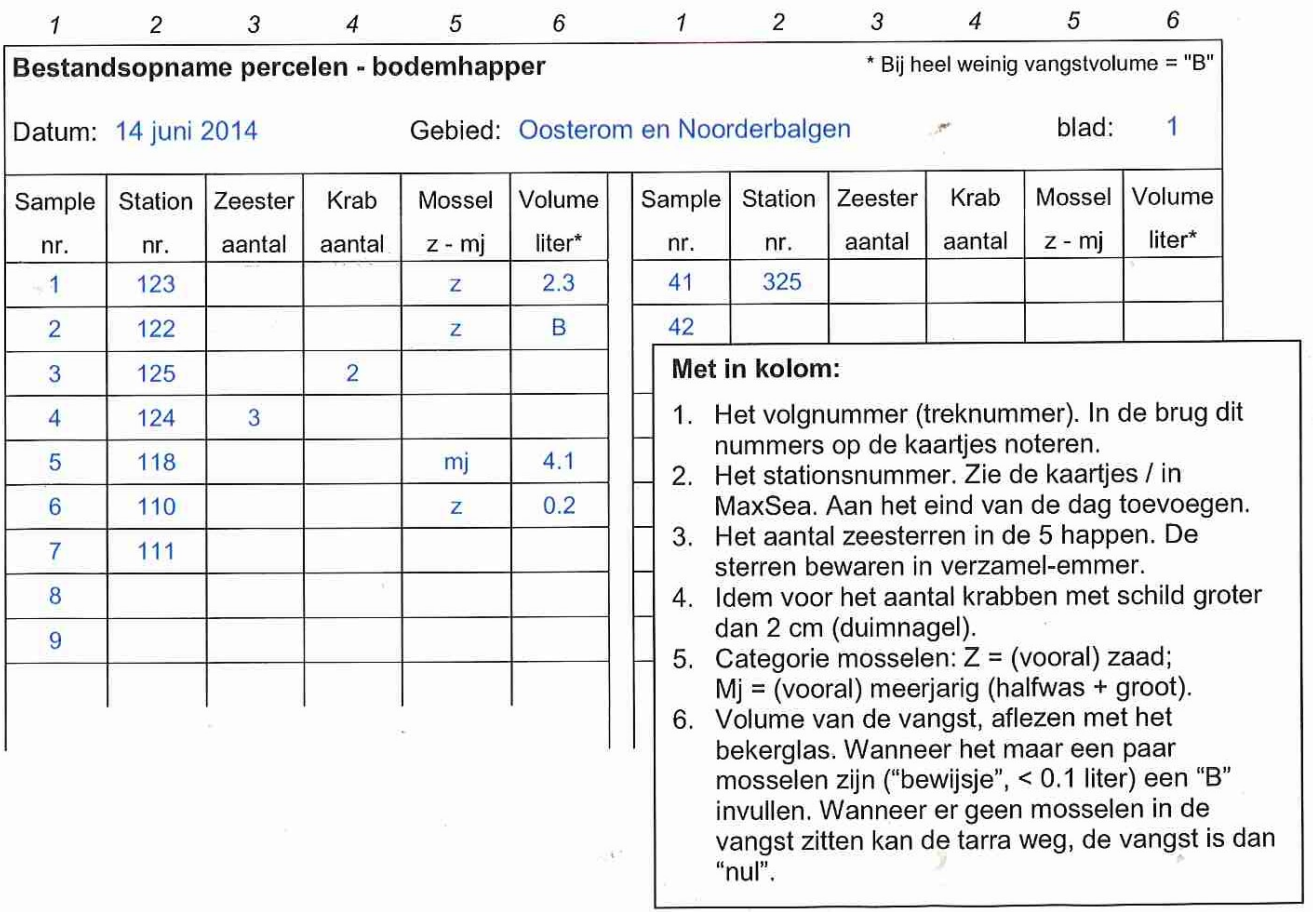


Uit de verzamelmanden wordt per dag een monster genomen en uitgezocht:

\section{Bepalen vangstvolume en het nemen van een subsample}

Van beide verzamelmanden vangstvolume bepalen in liters: grote zwarte emmer $=20$ liter, kleine zwarte emmer $=12$ liter of met maatbeker.

Volumes emmers graag nog even checken: Door de emmers met bekerglas te vullen met water.

- Vangst mengen en neem subsample op volume:

$>$ Zaad 3.5 liter = 1 doorzichtig emmertje, uit "zaad" verzamel-mand

Meerjarig 6 liter $=$ wit emmertje, uit de andere mand

- Wanneer de vangst kleiner is dan 3.5 resp. 6 liter, dan de hele vangst als monster nemen.

\section{Uitzoeken subsamples}

Zie ook het voorbeeld zoals ingevulde tabel op volgende pagina

- Beide monsters liefst helemaal uitzoeken

- Uitzoeken op zaad, halfwas (= meerjarig en $<45 \mathrm{~mm}$ ) en groot ( = meerj. en $>45 \mathrm{~mm}$ )

- Ontpokken

- Mosselen tellen en wegen, de kapotte mosselen alleen tellen

- Pokken wegen

- Zeesterren en krabben: tellen en wegen

- $\mathrm{Bij}$ later wegen de mosselen, krabben en zeesterren bewaren in water in verband met vochtverlies. 


\section{Bijlage 2 Kaarten mosseldichtheid per grootteklasse}



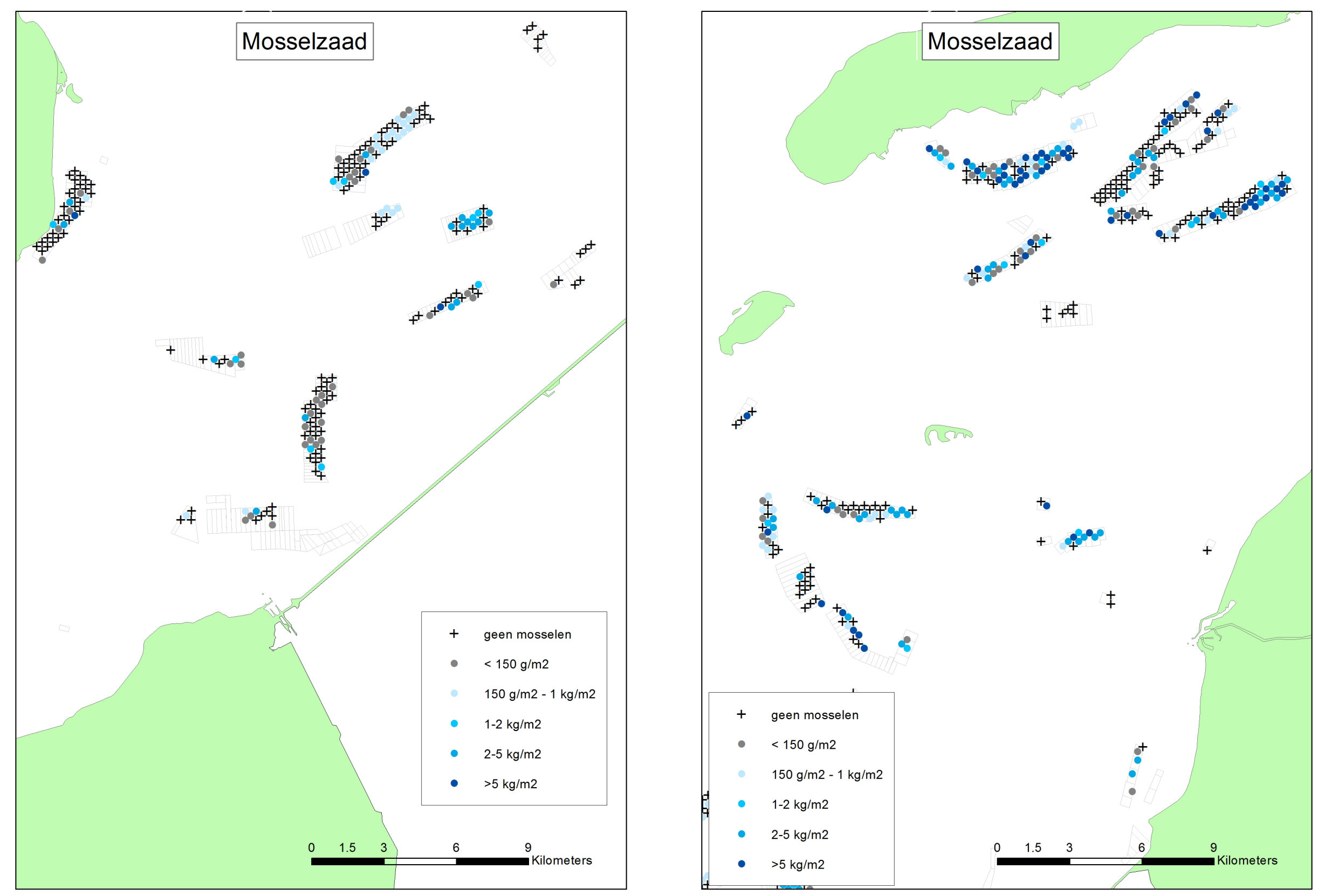

Wageningen Marine Research rapport C079/19 | 17 van 20 

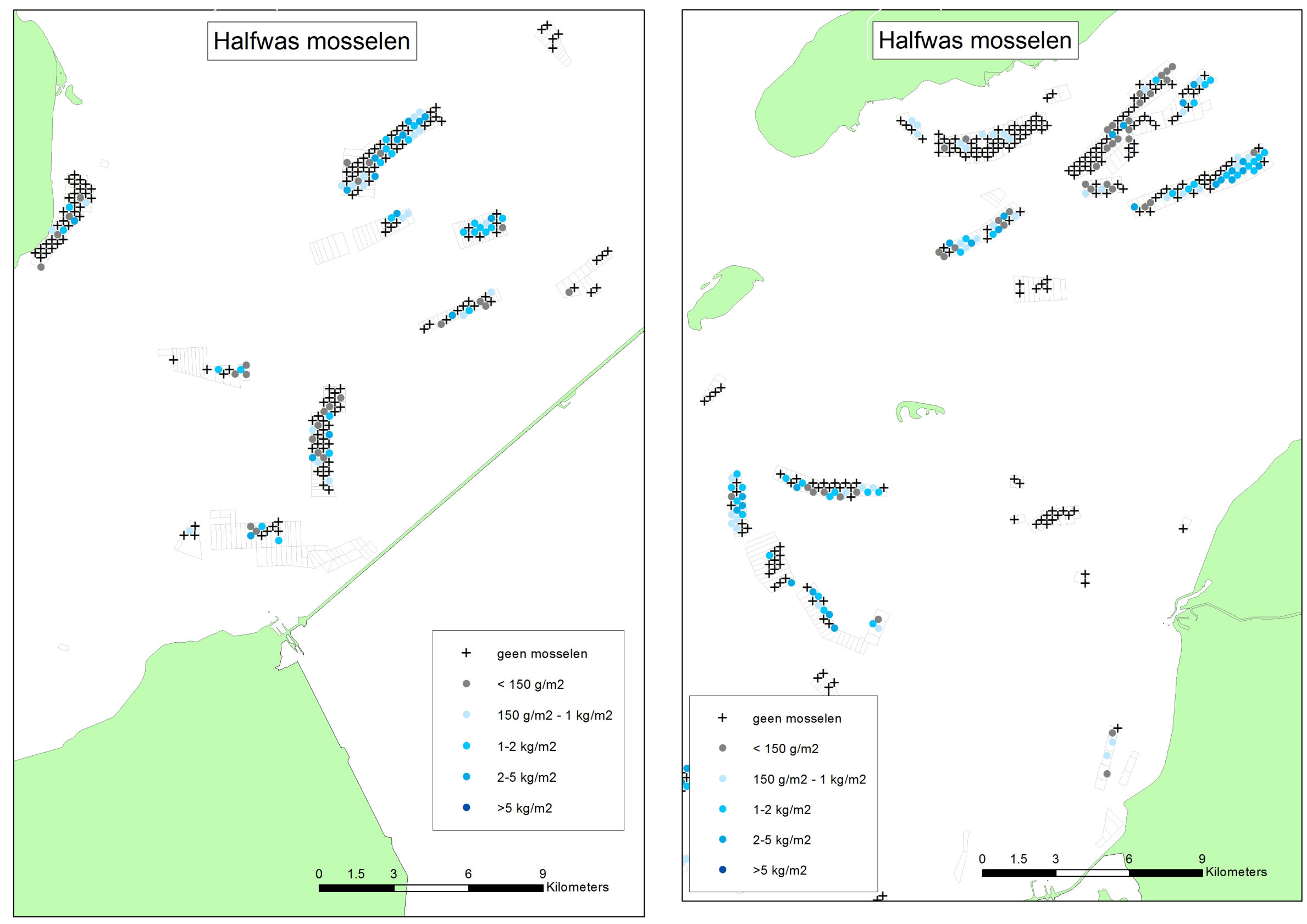

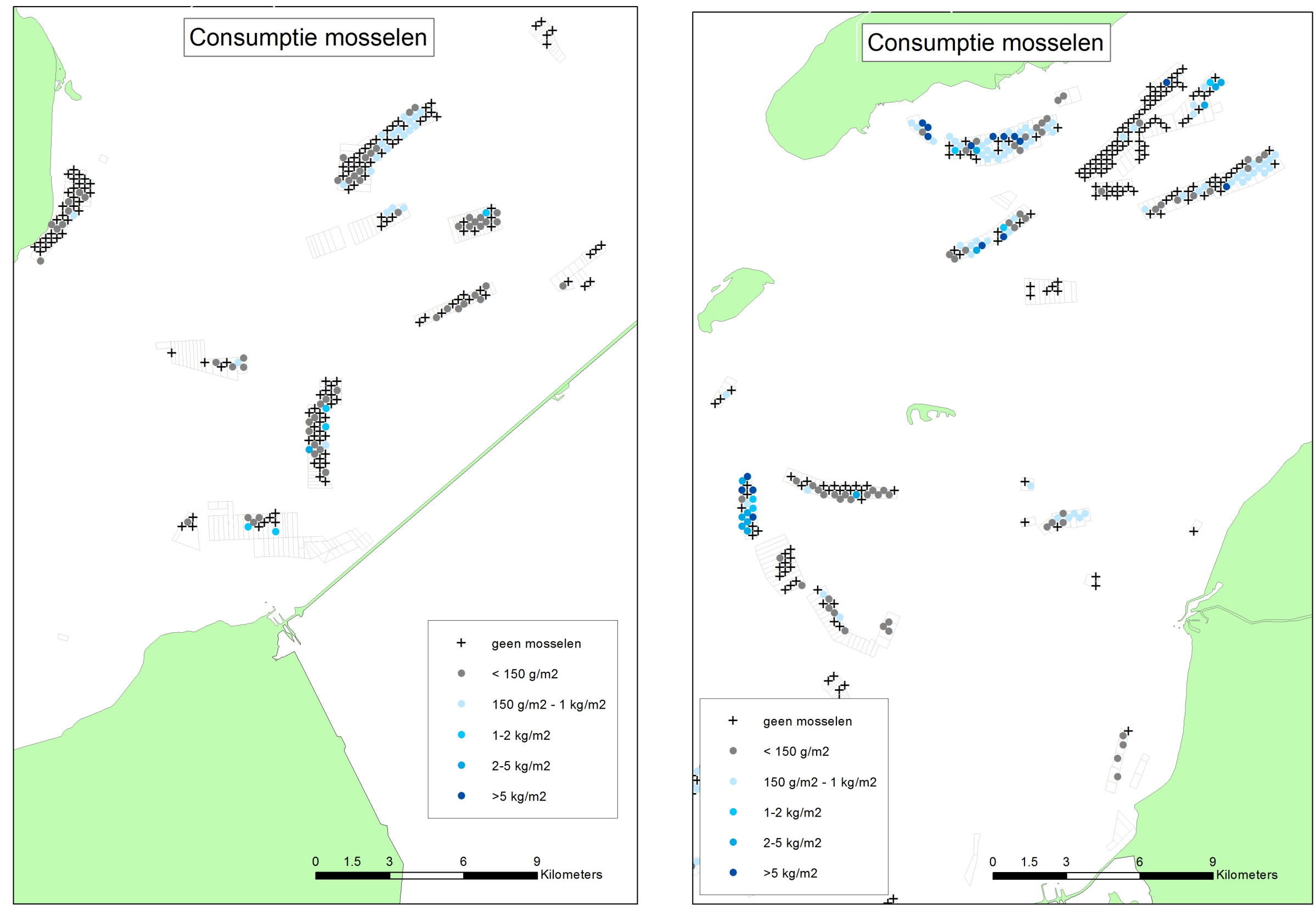

Wageningen Marine Research rapport c079/19 | 19 van 20 
Wageningen Marine Research

T: +31(0)317480900

E: marine-research@wur.nl

www.wur.nl/marine-research

Bezoekers adres:

- Ankerpark 27, 1781 AG Den Helder

- Korringaweg 7, 4401 NT Yerseke

- Haringkade 1, 1976 CP IJmuiden
Wageningen Marine Research levert met kennis, onafhankelijk wetenschappelijk onderzoek en advies een wezenlijke bijdrage aan een duurzamer, zorgvuldiger beheer, gebruik en bescherming van de natuurlijke rijkdommen in zee-, kust- en zoetwatergebieden.
Wageningen Marine Research is onderdeel van Wageningen University \& Research. Wageningen University \& Research is het samenwerkingsverband tussen Wageningen University en Stichting Wageningen Research en heeft als missie: 'To explore the potential of nature to improve the quality of life' 